\title{
Sensitivity of primary production to different eddy parameterizations: A case study of the spring bloom development in the northwestern Mediterranean Sea
}

\author{
by Marina Lévy ${ }^{1}$, Martin Visbeck ${ }^{2}$ and Naomi Naik ${ }^{2}$
}

\begin{abstract}
The abilities of the Gent and McWilliams (1990) (GM) and Horizontal Diffusion (HD) eddyparameterizations to represent the mesoscale effects relevant for primary production are compared and analyzed. Following Lévy et al. (1999a), this is done in the case study of the spring bloom that follows the formation of a dense water patch in the northwestern Mediterranean Sea. It is shown that, unlike HD, the use of the GM parameterization can capture many aspects of the primary production enhancement associated with the restratifying action of mesoscale eddies. However, predicted primary production, when using the GM parameterization, is sensitive to the GM's parameter set, and particularly to the maximum value of the lateral mixing coefficient, $k_{\max }$.
\end{abstract}

\section{Introduction}

The quantification of primary production is a major objective in the study of the oceanic carbon cycle. Indeed, primary production is one of the main biological processes that controls the inorganic carbon content of the surface layer, and therefore the air-sea $\mathrm{CO}_{2}$ flux, as it involves photosynthetic fixation of $\mathrm{CO}_{2}$. In middle and high latitudes, primary production observations have revealed significant variability on the scale of eddies (Gower et al., 1980; Watson et al., 1991; Robinson et al., 1993), which has motivated a number of studies aimed at understanding the processes driving this variability (Flierl and Davis, 1993; Yoshimori and Kishi, 1994; McGillicuddy et al., 1995; Dadou et al., 1996; Moisan et al., 1996; Smith et al., 1996; Lévy et al., 1999a, hereafter referred as LMM). Two main mechanisms have come out of these studies: in nutrient stress conditions, the upward vertical circulation associated with eddy dynamics can transfer nutrients to the enlightened surface layer; in light stress conditions, eddy-induced mixed-layer shoaling can locally increase the mean exposure time of the photosynthetic organisms. In both cases, it appears that mesoscale dynamics can act as an enhancer of primary production, by reducing the dominant stress. Basin scale (Oschlies and Garçon, 1998) or more regional studies (Lévy et al., 1998b) agree on a $30 \%$ or more enhancement of primary production by mesoscale

1. LODYC, Université Pierre et Marie Curie, 5 Place Jussieu, 75252 Paris Cedex 05, France email: marina.levy@ipsl.jussieu.fr

2. Lamont Doherty Geological Observatory, Columbia University, Palisades, New York, 10964, U.S.A. 
dynamics. Such studies are based on the comparison of primary production predictions between eddy-resolving and noneddy-resolving models. They emphasize the need to actually resolve mesoscale eddies in order to get accurate primary production predictions.

However, such a need is in serious conflict with the enormous computer requirement of eddy-resolving ecosystem models. In fact, it is not yet possible to run eddy-resolving ocean circulation models on climatic time scales, even when using the most powerful computers. The necessity to compute the evolution of a number of additional tracers in order to predict primary production makes the issue all the more relevant. In consideration of this, an appealing alternative is the use of parameterizations to represent the important aspects of mesoscale eddies in coarse resolution models. The representation of eddies in coarse resolution models has long been rather rudimentary; tracers were diffused down the large-scale horizontal gradient, essentially in order to insure numerical stability and without reliable physical justification. In recent years, a lot of effort has been put into the development of a physically based parameterization of eddy transfer properties (Gent and McWilliams, 1990; Gent et al., 1995; Treguier et al., 1997; Visbeck et al., 1997; Griffies et al., 1998). All these works rely on the ideas first developed by Gent and McWilliams (1990). Basically, the effect of the eddies is expressed in terms of downgradient isopycnal thickness diffusion, or equivalently as an along-isopycnal mixing process together with the use of an eddy-induced transport in addition to the mean large-scale transport (Gent et al., 1995). The Gent and McWilliams's parameterization provides a sink of mean available potential energy, an important aspect of baroclinic instability. It has been applied with some success to the transport of heat and salt and yielded encouraging improvement of modeled ocean circulation (Danabasoglu et al., 1994; Böning et al., 1995; Danabasoglu and McWilliams, 1995; Duffy et al., 1997).

The aim of this paper is not to develop or even improve any parameterization for primary production purposes; we propose to test the abilities of the existing parameterizations to incorporate the mesoscale effects that are relevant for primary production. Following LMM, this is done in the case study of the spring bloom that follows the formation of a dense water patch in the northwestern Mediterranean Sea. In this specific study, there is little nutrient stress and primary production is mainly limited by the availability of light and hence controlled by the vertical mixing depth. Therefore, the issue of the eddy-induced supply of nutrients will not be central to this problem. The breakup of the dense water patch is achieved by the action of mesoscale eddies which strongly influence the mixing depth, and therefore primary production. However, primarily during this transition period between winter and spring, the large-scale vertical mixing is controlled by the atmospheric forcing. The eddy parameterizations are therefore evaluated on their capacity to predict the breakup of the dense water patch, the mixing depth, and eventually the resulting primary production, by comparison with experiments where mesoscale activity is explicitly resolved, and within different atmospheric forcing scenarios. The paper is organized as follows. After describing the model and the parameterizations, the mesoscale dynamics and their impact on primary production are discussed on the basis of an eddy-resolving 
experiment with no net atmospheric forcing. Then, the predictive abilities of the two parameterizations are compared within this specific scenario, and sensitivity studies are carried out on the parameters involved in these parameterizations. Finally, the parameterizations are compared in a series of atmospherically forced experiments.

\section{Description of the model and of the parameterizations}

The model consists of a primary production model embedded in a primitive equation model. The configuration is that of LMM, although a different primitive equation model is used (and therefore different numerics), as well as slightly different initial conditions. A linear equation of state is assumed, leaving temperature as the only thermodynamical tracer. The evolutions of temperature and momentum are solved using the primitive equation model LOAM (Lamont Ocean Atmospheric mixed-layer Model, Gent and Cane, 1989; Naik, 1998; Rodgers et al., 1999). Vertical eddy viscosity and eddy diffusivity coefficients are assumed to vary as a function of the local Richardson number according to the parameterization of Pacanowski and Philander (1981). In addition, a convective adjustment algorithm is used to parameterize convective processes. A more sophisticated representation of the mixed-layer physics (Blanke and Delecluse, 1993) is used in LMM, and does not significantly modify the results, which justifies the vertical mixing parameterization used in the present work. Equations are solved on an A-grid, and a centered finite difference scheme is used for advection. The NPZD primary production model has four prognostic variables: Nutrients, Phytoplankton, Zooplankton and Detritus, expressed in nitrogen units (mmole $\mathrm{N} \mathrm{m}^{-3}$ ). It is fully described in the Appendix. The Eulerian time evolution of each of the four variables is controlled by biogeochemical processes, advection, and diffusion. The integration is done on-line with the dynamics, using the identical scheme as for temperature. Because of the dispersion errors associated with the centered advection scheme, negative values of biological tracers are generated. These negative values are then set to zero, which represents an input of nitrogen that is never in excess of $10^{-7} \mathrm{mmol} \mathrm{N} \mathrm{m}^{-3}$. Note that in LMM, a positive advection scheme is used, which suppresses the need for such a cut-off, and does not modify the results.

The domain is a closed, square basin on a $f$-plane centered at $42 \mathrm{~N}, 300 \mathrm{~km}$ wide with a constant depth of $2.5 \mathrm{~km}$. There are twenty vertical layers, twelve of which are used for the first 130 meters. No slip conditions are applied along solid boundaries. The initial density field is set with a homogeneous dense water patch with a radius of approximately $20 \mathrm{~km}$ in the center of the domain. Outside the patch, density is relaxed to a background stratification, within a horizontal gradient area of $80 \mathrm{~km}$. The background density profile is homogeneous in depth over the first $80 \mathrm{~m}$. The first internal Rossby radii of this stratification are $8.4 \mathrm{~km}, 3.8 \mathrm{~km}$ and $2.5 \mathrm{~km}$. The patch of dense water is perturbed with a sinusoid of mode seven and $1 \mathrm{~km}$ in amplitude, corresponding to the most unstable mode in the framework of the two-layer theory (Pedlosky, 1987). This first perturbation is uniform on the vertical. A white noise perturbation is then added to the surface density field (which is not the case in LMM), whose amplitude is allowed to reach $10 \%$ of the density gradient 
between the center of the patch and the background area; this helps in preventing the excitation of grid modes. This initial density structure is typical of the situation in the MEDOC area (northwestern Mediterranean Sea) after the preconditioning and violent mixing phase of deep water formation (Medoc Group, 1970; Leaman and Schott, 1987; Schott et al., 1996). The choice for a meander-free initial state assumes that the time for convection is short compared with the growth rate of the instabilities. Experiments start from rest and without any spin-up (unlike in LMM), in order to always start from the same conditions. The experiments are run for 30 days. Initial phytoplankton and nutrient concentrations are derived from the initial density field, according to observations in the MEDOC area (Coste et al., 1972; Jacques et al., 1973); high densities (in the center of the convective region) are correlated with high nitrate and low phytoplankton concentrations, such that nitrate and phytoplankton concentrations in the denser waters are 6 and 0.01 mmole $\mathrm{m}^{-3}$ respectively, while they are 1 and $0.1 \mathrm{mmole}^{-3}$ in the lighter waters. Zooplankton and detritus initial concentrations are initially homogeneously set to low values $\left(0.005 \mathrm{mmol} \mathrm{N} \mathrm{m}^{-3}\right)$.

Atmospheric forcings are applied with no space variability. In a first series of experiments (hereafter referred as "no net flux" experiments), we assume a zero wind stress and zero net heat flux, held constant with time. The surface heat flux is split into a penetrative solar flux of $150 \mathrm{~W} \mathrm{~m}^{-2}$, and an outward flux of $-150 \mathrm{~W} \mathrm{~m}^{-2}$. The penetration of the solar radiation is responsible for the generation of static instabilities (and is therefore an important source of vertical mixing) as it enables the heating of the first few layers while only the surface layer is cooled. In a second series of experiments, the solar flux is perturbed; in the case of the "winter" (respectively "spring") experiments, the perturbation is a time constant of $-25 \mathrm{~W} \mathrm{~m}^{-2}$ (respectively $+25 \mathrm{~W} \mathrm{~m}^{-2}$ ); in the case of the "T7" (respectively "T3") experiment, the perturbation is a sinusoïde with a $25 \mathrm{~W} \mathrm{~m}^{-2}$ amplitude and a 7.5 days (respectively 3.75 days) half-period. These half-periods are representative of the duration of a Mistral wind burst.

Two types of experiments are performed, eddy-resolving experiments (ER experiments), and coarse resolution experiments ( $\mathrm{CR}$ experiments). Table 1 summarizes the characteristics of all experiments discussed in the paper. In the ER runs, the horizontal grid spacing is set to the value of the third internal Rossby radius of deformation, $2.5 \mathrm{~km}$; mesoscale eddies are explicitly resolved. Horizontal mixing of heat and momentum is included through fourth-order Shapiro filters (Shapiro, 1970), which insures numerical stability by dissipating the smallest scales. The time step is 18 minutes. In the CR runs, the grid spacing is $10 \mathrm{~km}$, which does not permit the resolution of mesoscale eddies considering the small value of the Rossby radius. The time step is 12 minutes. Horizontal mixing of momentum is still included through fourth-order Shapiro filters. The eddy transfer activity is parameterized in two different fashions, either by horizontal diffusion (hereafter HD parameterization), or by using the Gent and McWilliams (1990) (hereafter GM) parameterization.

The isopycnal thickness diffusion involved in GM is implemented by rotating a generic tracer diffusion tensor in such a way that its major axis is parallel to the local density 
Table 1. Description of the runs presented in this paper.

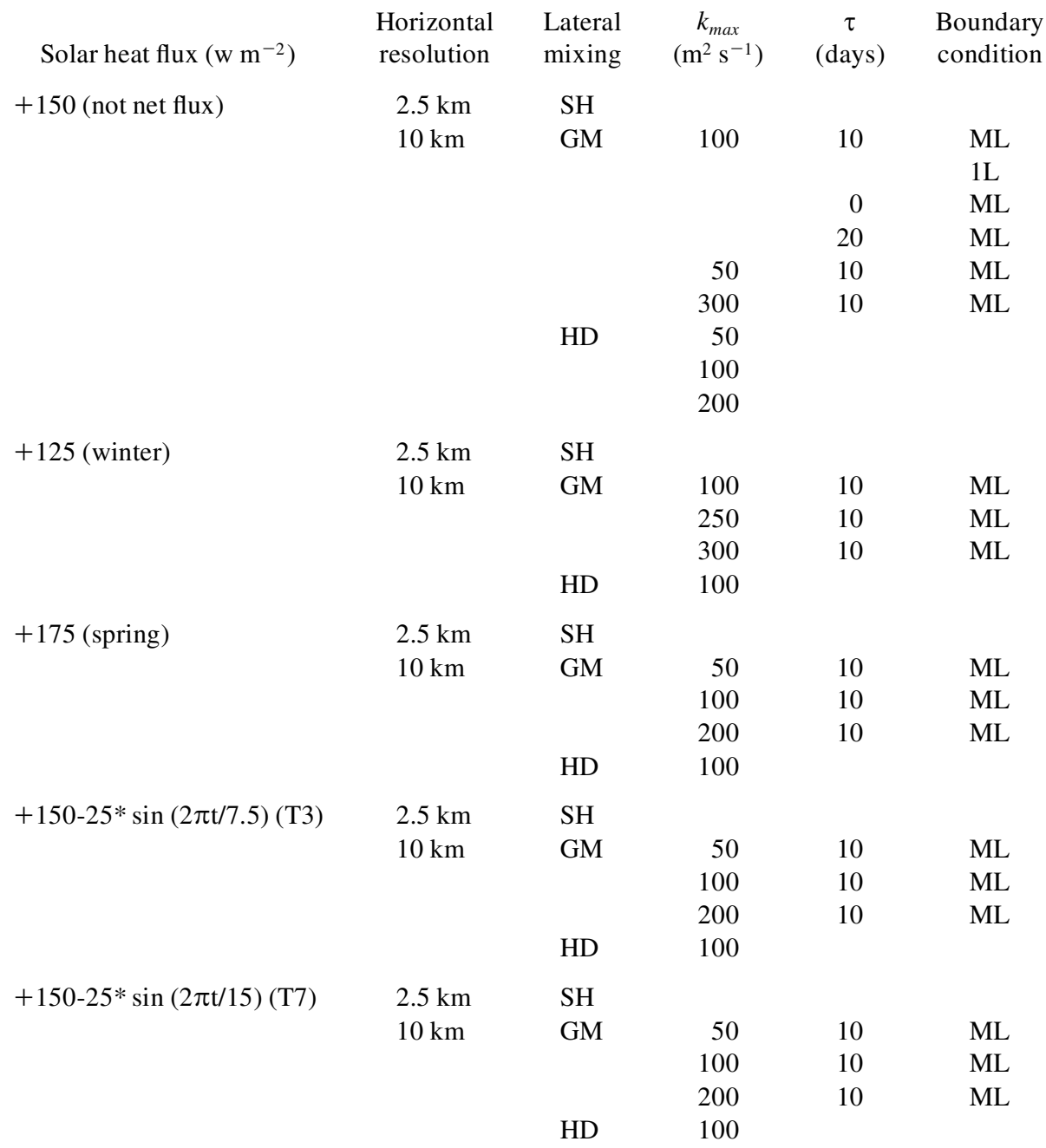

GM: Gent and Mc Williams (1990) scheme.

HD: Horizontal Diffusion.

$\mathrm{SH}$ : Shapiro filter.

$k_{\text {max }}$ : maximum $k$ (lateral mixing coefficient) value.

$\tau$ : $k$ 's growth rate.

ML: Mixed-Layer boundary condition for $k$.

1L: first model Level boundary condition for $k$. 
gradient (see Griffies et al., 1998, for a recent review). In order to avoid grid scale instabilities the model density field is filtered prior to the computation of the density gradients. We have also made use of the simplified numerics that arise for the special case where the diffusion coefficients for isopycnal mixing and the eddy induced transfer velocities are equal (Griffies et al., 1998). However, although there is some evidence that the diffusion coefficient should vary spatially (Figueroa and Olson, 1994; Rix and Willebrand, 1996; Visbeck et al., 1997), we have only considered constant space coefficients. This approximation could be justified by the small extend of the domain, and the fact that mixing terms cancel anyway outside of the front, where there are no horizontal gradients. Moreover, in order to account for the growth rate of the instabilities, the diffusion coefficient is not initially set to its maximal value, $k_{\max }$, but is assumed to exponentially grow toward this value with a prescribed growth rate. We have set this growth rate to equal the time needed for the meanders to appear in the ER simulation, i.e., 10 days.

Another issue with the GM parameterization concerns the vertical profile of the diffusion coefficient. In order to satisfy the no flux conditions at the surface and bottom, the diffusivity needs to approach zero at both boundaries. However, there is a choice about how rapidly one expects that to happen. Technically this can be done by just setting the diffusivity to zero in the upper and lower layers. However, since nothing is special about the thickness of the uppermost grid point we have chosen to linearly relax the diffusivity from its maximum interior value at the base of the mixed layer toward zero at the surface. This assumes that the eddy flux is equally distributed over the mixed layer. At the bottom, we just set the last coefficient to zero.

\section{Eddy-resolving experiment-Case with no net forcing}

The dynamics of the no net flux-ER experiment and their impact on primary production are fully described in LMM, therefore only the basic mechanisms involved in the breakup of the dense water patch and in the resulting phytoplankton bloom are summarized below. The release of the available potential energy contained within the dense water patch occurs through the development of mixed barotropic-baroclinic instabilities. The signature of these instabilities on the surface density field appears in the form of meanders along the front that defines the neutrally stable column. A time series of the surface density field (Fig. 1) shows the development of seven meanders at the outer edge of the convective region (day 15) having wavelengths of $\sim 50 \mathrm{~km}$ (corresponding to the first baroclinic mode), which eventually break into seven cyclonic eddies (day 25). Basically, they serve as vehicles for the transfer of water masses, by sinking the denser waters out of the convective zone and at the same time upwelling lighter peripheral waters toward the center. Consequently, these mesoscale instabilities are responsible for the collapse of the dense water patch. The axial symmetry of the problem allows for azimuthal averages across the frontal zone, and the mean action of the instabilities can be depicted by looking at such averaged properties as a function of depth and distance from the center of the convective 

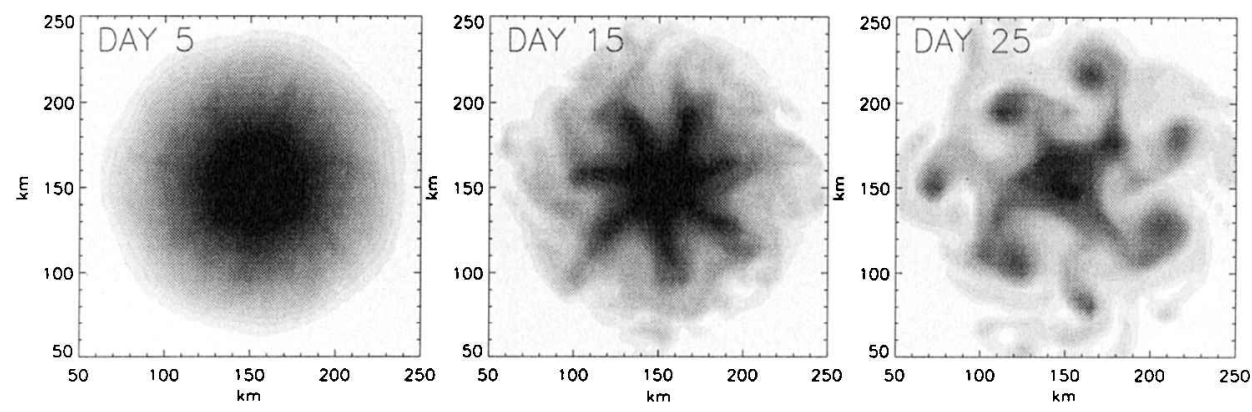

Density

$\begin{array}{llllllll}28.4 & 28.5 & 28.6 & 28.7 & 28.8 & 28.9 & 29 & 29.1\end{array}$

Figure 1. Time series of the surface density field in the ER no net flux experiment, showing the development of meanders and eddies in the frontal zone surrounding the dense water patch.

patch. Hence, a time series of the azimuthally averaged density field close to the surface shows the progressive capping of the dense water patch by lighter waters (Fig. 2).

The mixed layer (diagnosed on a vertical density gradient criteria of $0.01 \mathrm{~kg} \mathrm{~m}^{-3}$ ) is assumed to be representative of the surface layer over which tracers are being mixed (commonly referred as the mixing layer). The initial mixed-layer depth is thus set by the initial stratification: it reaches the bottom in the convective area $(2500 \mathrm{~m})$, and is bounded by the thermocline at $80 \mathrm{~m}$ elsewhere. As soon as the instabilities develop, the transport of warmer waters from the stratified area toward the convective site across the frontal zone is responsible for the sloping of the isopycnals and hence for the shoaling of the mixed layer. If one follows the cyclonic geostrophic circulation along the meanders and around the convective site, it appears that this warm water transport occurs in the meanders' trough, while cold waters are transported in the opposite direction in the meanders' crests. Consequently, the mixed layer is only shoaled in the meander troughs, where it can be as thin as $20 \mathrm{~m}$, while it remains at $80 \mathrm{~m}$ in the meander crests (see figure in LMM). Azimuthal averages of the mixed layer depth (Fig. 2) do not show this succession of highs and lows around the frontal zone, but emphasize the mean decrease of the mixed-layer depth in the frontal zone (to about $40 \mathrm{~m}$ ) generated by the mean transport.

Scatter plots of primary production against mixed-layer depth and surface nutrients (Fig. 3) show that there is no obvious relationship between primary production and nutrients, whereas primary production clearly increases when the mixed-layer depth decreases. This gives evidence that primary production is light, but not nutrient, stressed. Indeed, the mean exposure time of the phytoplankton cells to sunlight is inversely correlated with the mixed-layer depth. Consequently, and as shown by the azimuthally averaged production, the majority of phytoplankton production is obtained in the frontal 

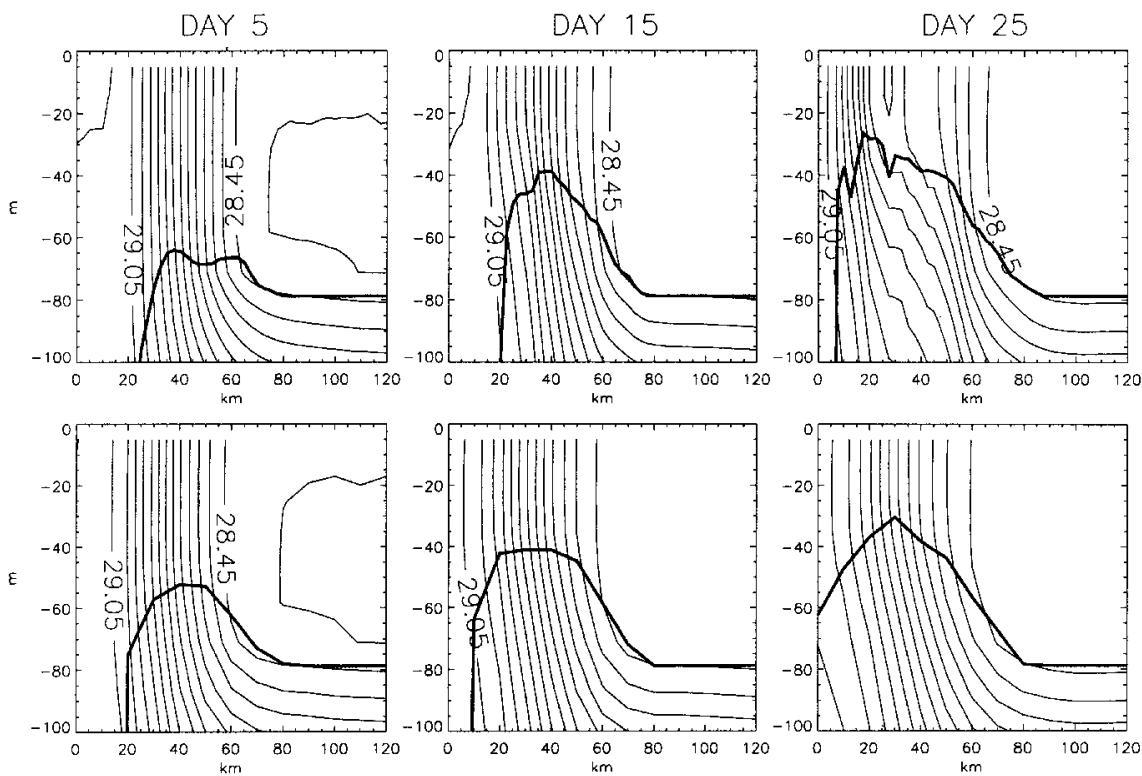

$C R-G M$
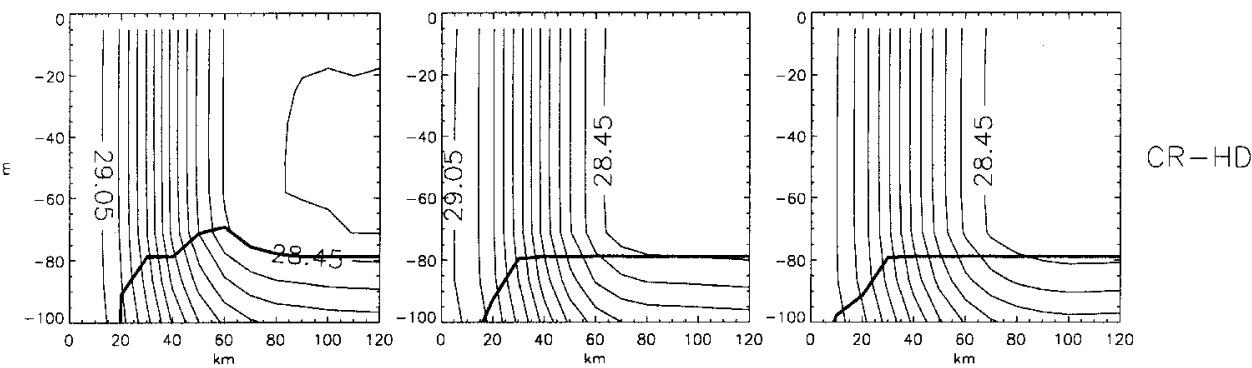

Figure 2. Time series of the azimuthally averaged density field (black contours, contour interval is $0.05 \mathrm{~kg} \mathrm{~m}^{-3}$ ) and of the azimuthally averaged mixed-layer depth (thick black line) for the ER, the CR-GM (with $k_{\max }=100 \mathrm{~m}^{2} \mathrm{~s}^{-1}, \tau=10$ days, ML-boundary condition) and the CR-HD (with $\left.k=100 \mathrm{~m}^{2} \mathrm{~s}^{-1}\right)$ no net flux experiments.

zone, where the mixed layer is the shallowest (Fig. 4). Zooplankton and detritus remain in small concentrations during all experiments and will not be considered hereafter.

\section{CR-HD and CR-GM experiments: Case with no net forcing}

In the CR experiments, the eddies are not resolved, therefore variability in all fields is primarily across-front and not along-front. In other words, the problem becomes essentially two-dimensional in space. When using the GM parameterization (CR-GM experiment), the eddy-induced transport mimics the three-dimensional redistribution of water masses achieved by the eddies (Fig. 5). In particular, warm waters are transported from the stratified area toward the center, causing the sloping of the isopycnals in the frontal area associated with the shoaling of the mixed layer to about $40 \mathrm{~m}$ (Fig. 2, day 15). The GM 

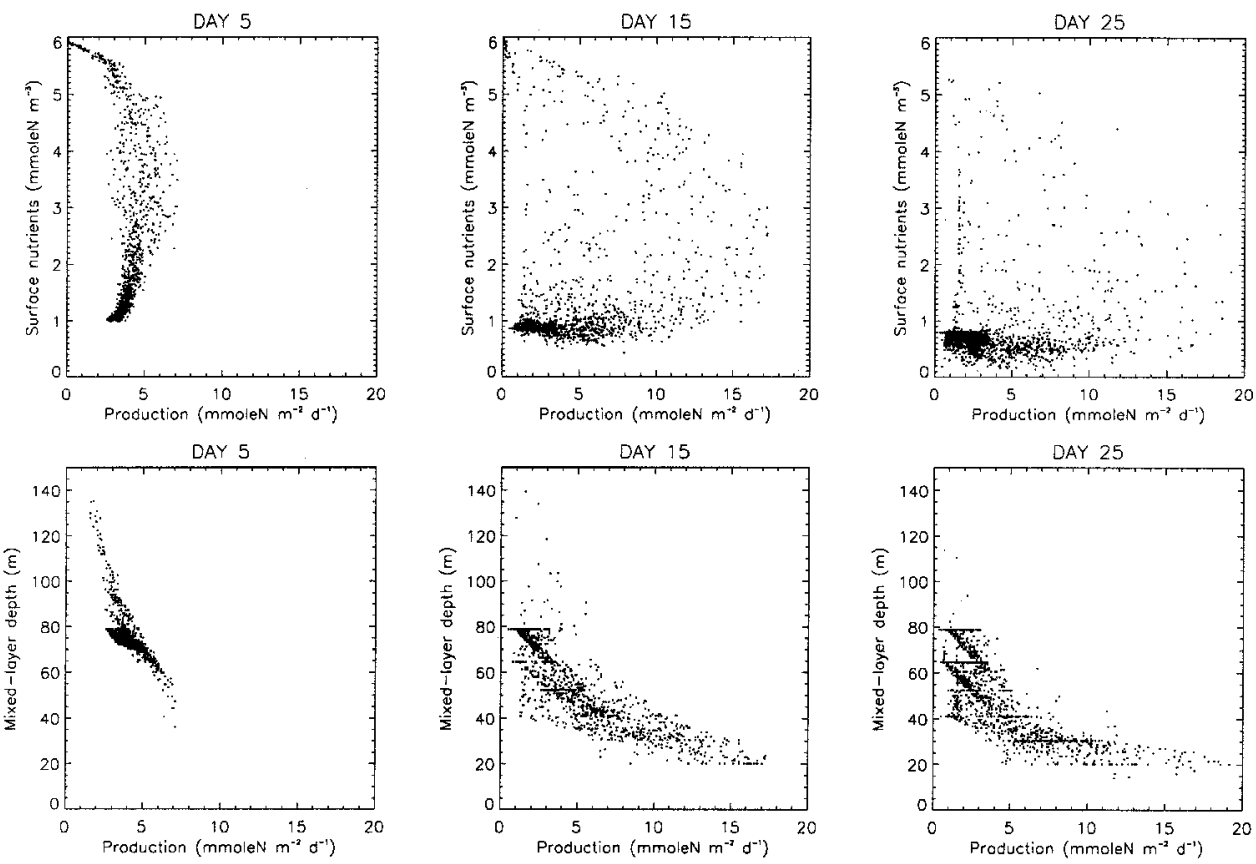

Figure 3. Scatter diagram time series of production against surface nutrients (top figures) and production against mixed-layer depth (bottom figures) for the ER no net flux experiment. Bottom figures show the increase of production with decreasing mixed-layer depth; higher production levels are reached toward the end of the simulation, when the shallowest mixed layers are obtained. In the top figures, the decrease of production toward high nutrient values, which is most obvious at day 5 , is due to the fact that the highest nutrient values are initially confined within the center of the dense water patch, where the mixed layer is the deepest; highest production values are obtained for nutrient concentrations ranging 1 to $4 \mathrm{mmoleN} \mathrm{m}^{-3}$, which are located in the frontal zone.

parameterization, therefore, reproduces with good accuracy the action of the eddies on the collapse of the chimney, as well as the associated mixed-layer depth shoaling in the frontal area. Furthermore, the averaged mixed-layer depth across the dense water patch is very similar in the ER and CR-GM experiments; it should be kept in mind however that this depth is indeed an average between the troughs and the crests values in the case of the ER experiment, while it is homogeneous in the CR-GM experiment. Since the averaged behavior of the mixed layer is correct, primary production shows the same features than in the ER experiment, with minimum values at the center of the convective patch, and maximum values at the front (Fig. 4). Moreover, the order of magnitude of the azimuthal productivities in the ER and CR-GM experiments are similar. However, vertical distributions show systematic differences; maximum values in the ER experiment are about $25 \%$ larger, and are confined in a thinner layer (day 15). Indeed, in the ER experiments, high productivities occur in the meander troughs, where the mixed layer is shallower than its averaged depth; therefore, when averaging productivities along the crests and troughs, high 

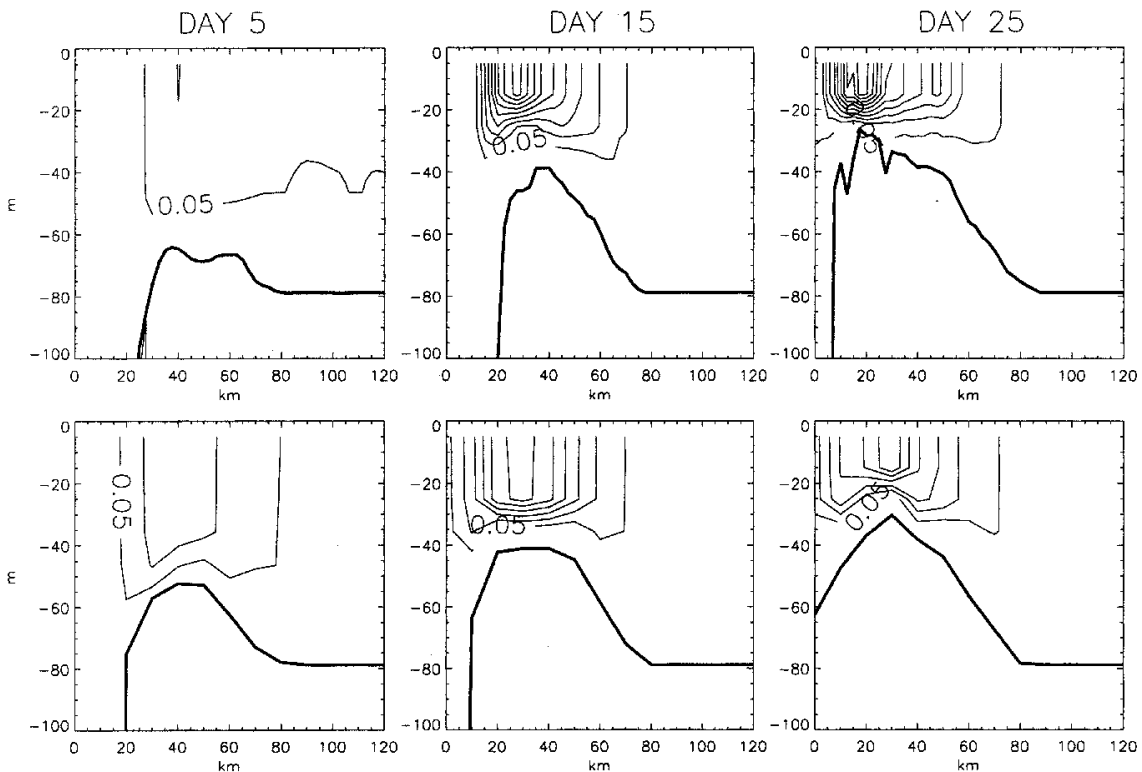

$C R-G M$
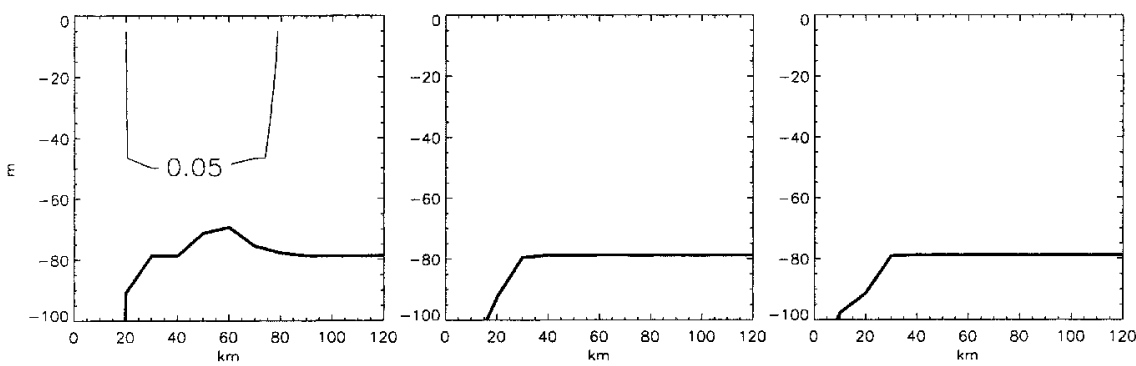

$C R-H D$

Figure 4. Time series of the azimuthally averaged primary production field (black contours, contour interval is 0.05 mmole $\mathrm{m} \mathrm{m}^{-3} \mathrm{~d}^{-1}$ ) and of the azimuthally averaged mixed-layer depth (thick black line) for the ER, the CR-GM and the CR-HD no net flux experiments.

values show up in a thin layer, corresponding approximately to the depth of the mixed layer in the meanders' troughs. By contrast, production in the GM experiment is more vertically diluted, as there are no such localized regions of very high production confined to a thin mixed layer.

When the HD parameterization is used, the whole process is horizontal (Fig. 5). The horizontal density gradient stretches out, which tends to decrease the density in the center of the convective area, but by horizontal mixing with the lighter waters of the background area instead of three-dimensional redistribution (Fig. 2). Therefore, the mixed layer remains approximately at the same depth during the whole process, except in the very center where it progressively shallows. As there is no mixed-layer depth minima in the frontal zone, there is hardly any production at all (Fig. 4). Thus, the HD parameterization very badly represents both the density and the biology. 


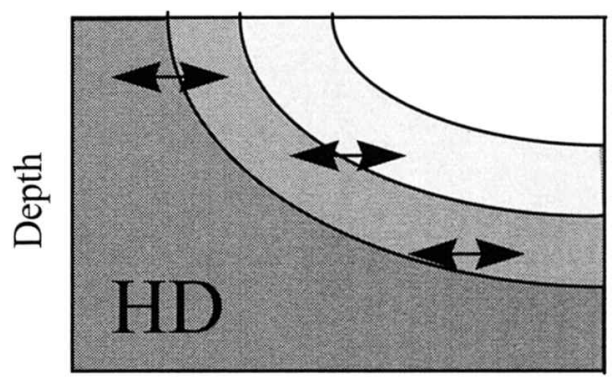

Density front

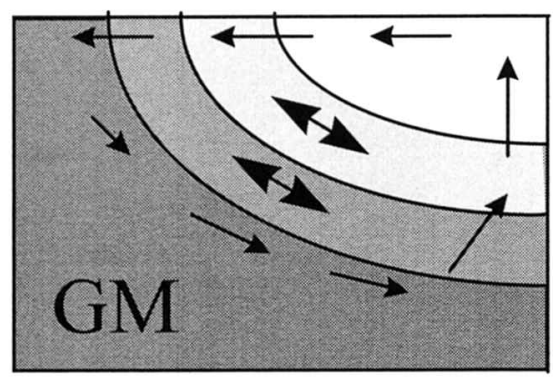

Density front

Figure 5. Diagrammatic representation of the action of the HD and the GM parameterizationsacross the front that surrounds the dense water patch. A vertical section of density across the front is represented, with lighter waters in white and denser waters in dark grey. Single-headed arrows represent the eddy-induced advection, while the double-headed arrows show the diffusive term, which is horizontal in the case of HD, and along isopycnals in the case of GM.

In order to more globally quantify the differences in primary production between the ER, the CR-GM and the CR-HD experiments, primary production is averaged over the $100 \mathrm{~km}$ radius domain and over the first $100 \mathrm{~m}$ (hereafter referred as global production). Global production cumulated with time (hereafter referred as cumulated production) are also shown for comparison (Fig. 6). As expected, both global and cumulated productions of the CR-HD experiment are much smaller than that of the CR-GM and ER experiments, which follow each other very closely. After 30 days, cumulated productions are almost equal for the ER and GM experiments (they differ by less than 5\%), but they are smaller by a factor of two in the HD experiment.

Global productions increase up to about the same value until days 17 and 20 respectively, and then start to decrease. In both the CR-GM and the ER experiments, the global production increase is obviously due to the progressive shoaling of the mixed layer. In order to diagnose the causes of the decrease of global production, we have plotted (Fig. 7) the time evolution of the total area of low nutrient concentrations $\left(<0,5 \mathrm{mmoleN} \mathrm{m}^{-3}\right)$, as
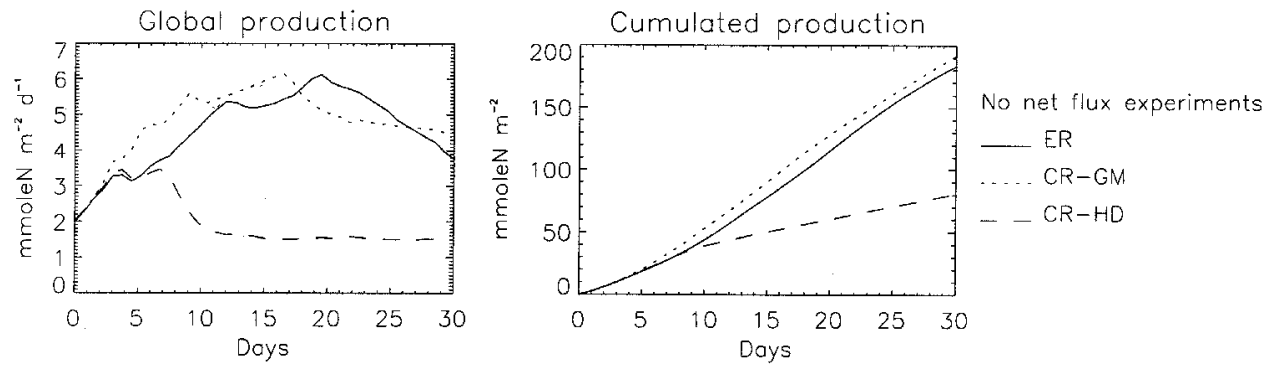

Figure 6. Time evolution of the global and cumulated productions for the ER, the CR-GM (with $k_{\max }=100 \mathrm{~m}^{2} \mathrm{~s}^{-1}, \tau=10$ days, ML-boundary condition) and the CR-HD (with $k=100 \mathrm{~m}^{2} \mathrm{~s}^{-1}$ ) no net flux experiments. 

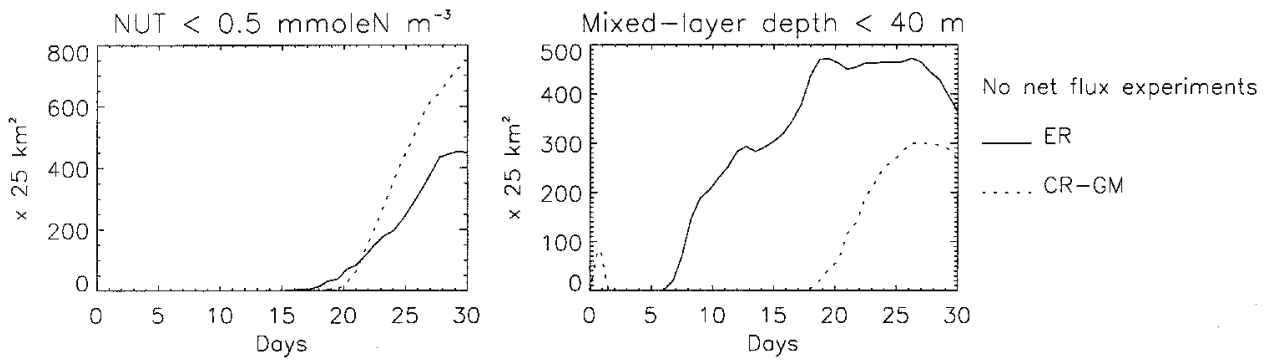

Figure 7. Time evolution of the surface area where the surface nutrient concentration is less then 0.5 mmole $\mathrm{N} \mathrm{m}^{-3}$ (left) and where the mixed-layer depth is below $40 \mathrm{~m}$ (right), for the ER and the CR-GM (with $k_{\max }=100 \mathrm{~m}^{2} \mathrm{~s}^{-1}, \tau=10$ days, ML-boundary condition) no net flux experiments.

well as the total area of shallow mixed layer $(<40 \mathrm{~m})$. These plots emphasize that in the ER experiment, the global decrease of production results from the conjunction of two effects: the slow depletion of nutrients, and the diminution of the area of shallowest mixed layer (in response to the dissipation of the instabilities); in the CR-GM experiment, the decrease is essentially due to nutrient depletion. It is not yet well understood why nutrient-depleted areas are more spread in the case of the CR-GM experiment (whereas global productions are similar); it might as well be due to the nonlinearity of the response of production to nutrient inputs, or to a too fast sinking of the nutrients by the GM eddy-induced advection (nutrients, which are more abundant in the dense waters, indeed sink together with them following the arrows in Fig. 5). In any case, this sets the limit of the agreement between the ER and the CR-GM experiments.

\section{Sensitivity of the results to the parameterizations parameters}

The purpose of this section is to study the sensitivity of the above results to the value of the diffusion coefficient $k$, for both the HD and the GM parameterizations, in terms of the variability of the global and time cumulated production. For comparison, results with the ER experiment are also shown (Fig. 8, solid line).

\section{a. Case of the HD parameterization}

Only space and time constant $k$ 's are used, and the sensitivity is carried on the value of this constant (Fig. 8a). As the horizontal mixing flux is proportional to $k$, higher $k$ values lead to a faster mixing rate and disappearance of the central convective area but cannot possibly lead to shallower mixed layers. As a result, global productivities are scarcely affected by a change in $k$, and therefore remain far below the ER global production.

\section{b. Case of the GM parameterization}

The diffusion coefficient $k$ used in the GM parameterization varies as a function of two parameters, $k_{\max }$ (maximum $k$ value) and $\tau$ ( $k$ 's growth rate); it also depends on a choice for the surface boundary layer. In the standard no net flux CR-GM experiment presented in the 

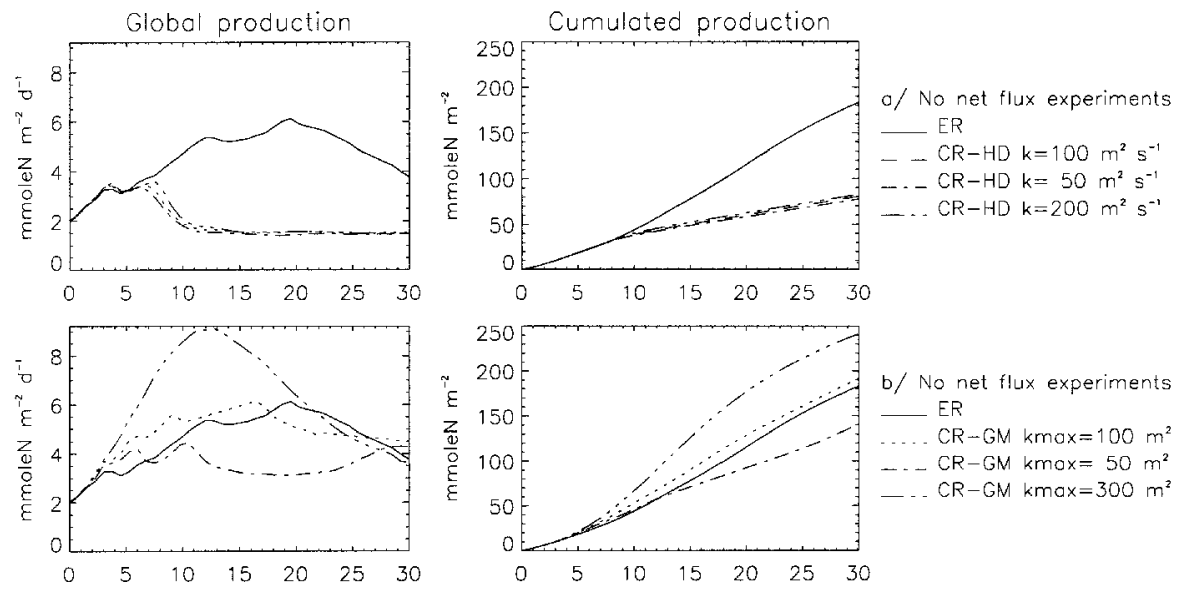

b/ No net flux experiments

ER

.... CR-GM kmox $=100 \mathrm{~m}^{2} \mathrm{~s}^{-1}$

$\ldots$. CR-GM kmox $=50 \mathrm{~m}^{2} \mathrm{~s}^{-1}$

- CR-GM kmox $=300 \mathrm{~m}^{2} \mathrm{~s}^{2}$
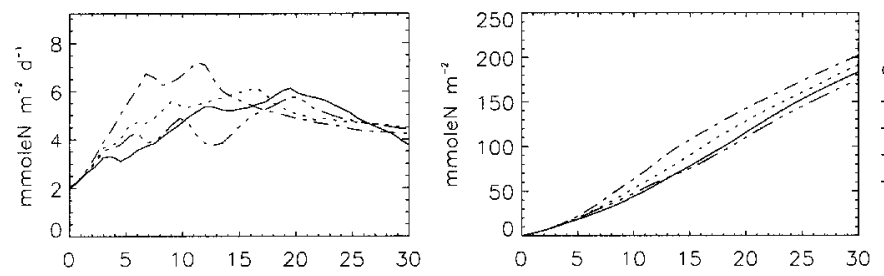

c/ No net flux experiments

- ER

... CR-GM tau $=10$ days

... CR-GM tau $=0$ doys

-. CR-GM tau $=20$ days
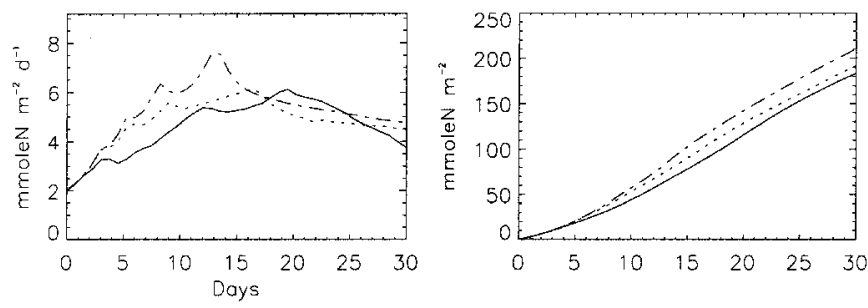

d) No net flux experiments

ER

.... CR-GM ML-boundary condition _. - CR-GM $1 L-$ boundary condition

Figure 8. Sensitivity studies. Time series of the global and cumulated productions, in a series of no net flux sensitivity experiments. The solid line is for the ER run. The dotted line is for the standard CR-GM experiment $\left(k_{\max }=100 \mathrm{~m}^{2} \mathrm{~s}^{-1}, \tau=10\right.$ days, ML-boundary condition $)$.

previous section, $k$ is computed with a $k_{\max }$ value of $100 \mathrm{~m}^{2} \mathrm{~s}^{-1}$, a growth rate $\tau$ of 10 days, and taking the mixed layer as the surface boundary layer (ML-boundary condition). In Figure 8b,c,d, this standard CR-GM experiment is depicted with a dotted-line.

Sensitivity to $k_{\max }$ is shown on Figure $8 \mathrm{~b}$; with a smaller $k_{\max }\left(50 \mathrm{~m}^{2} \mathrm{~s}^{-1}\right)$, the lateral transport of warm waters at the surface boundary is weaker, and therefore the associated restratification over the frontal area is less efficient. Azimuthally averaged mixed-layer depth minimal values remain below $60 \mathrm{~m}$ during the first 15 days of the experiment (not shown), whereas in the standard experiment they reach $55 \mathrm{~m}$ by day 5 and $40 \mathrm{~m}$ by day 15 (Fig. 2). As a result, global productivities are lower, and cumulated productivities underestimated by about $20 \%$. On the other hand if $k_{\max }$ is larger $\left(300 \mathrm{~m}^{2} \mathrm{~s}^{-1}\right)$, then restratification becomes more efficient (with minimal mixed-layer depth reaching $30 \mathrm{~m}$ by day 20). Consequently, productivities are now overestimated, and time cumulated productions are higher by about $20 \%$. 

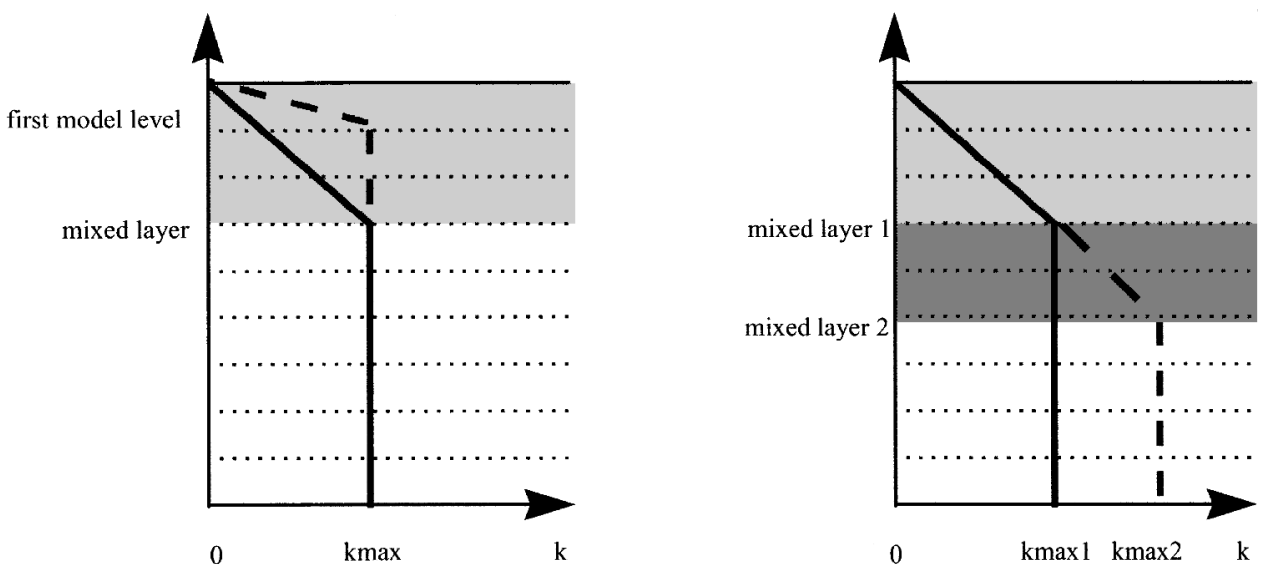

Figure 9. Diagrammatic representation of the surface boundary condition for $k$ and of its implications. Horizontal dotted lines show the first few vertical levels of the model. The mixed layer is shadded. Broken lines show the value of $k$ against depth: $k$ equals 0 at the surface, $k_{\text {max }}$ below a certain boundary layer, and increases linearly from 0 to $k_{\max }$ in between. For a given $k_{\max }$ value (left panel), $k$ within the mixed layer is bigger if the boundary layer is taken as the first model vertical layer (1L boundary condition, dotted line) than if it is taken as the mixed layer (ML boundary condition, solid line). In the case of a deeper mixed layer and when the ML boundary condition is used (right panel), the same $k$ value is obtained close to the surface for a higher value of $k_{\max }$.

Figure $8 \mathrm{c}$ shows the sensitivity to the growth rate. When $\tau$ equals 0 days, $k$ is immediately set to its maximum value, $k_{\max }$, and the parameterization acts instantaneously. Consequently, the mixed-layer depth minima is already reaching $40 \mathrm{~m}$ after one day, the global production plot shows a steeper initial slope, and reaches its maximum value more rapidly (day 11 instead of day 20). The opposite effect is obtained when the growth rate is changed to 20 days, with global production increasing at a slower rate, and reaching a maximum later in the experiment. However, cumulated production after 30 days only varies within a $5 \%$ range with $\tau$ varying from 0 to 20 days.

The sensitivity to the choice of the surface boundary layer is shown in Figure 8d. Instead of taking the boundary layer as the mixed layer, a sensitivity experiment is performed where the boundary conditions are confined within the first vertical model level, which goes from the surface down to $10 \mathrm{~m}$ depth (1L-boundary condition); global production increases faster in the $1 \mathrm{~L}$ than in the ML case, in a similar fashion to when a bigger $k_{\max }$ is used. This similarity is explained by the diagram on Figure 9 (left panel): in the $1 \mathrm{~L}$ case, the average value of the mixing coefficient over the mixed layer is larger, which gives similar productivities than when a larger value of $k_{\max }$ is used. Regarding time cumulated productivities, the choice between the $1 \mathrm{~L}$ and the ML boundary condition generates differences of about $10 \%$.

\section{Forced experiments}

The GM parameterization has proven to be more efficient compared to the HD parameterization in predicting production, within a particular scenario where there was no 

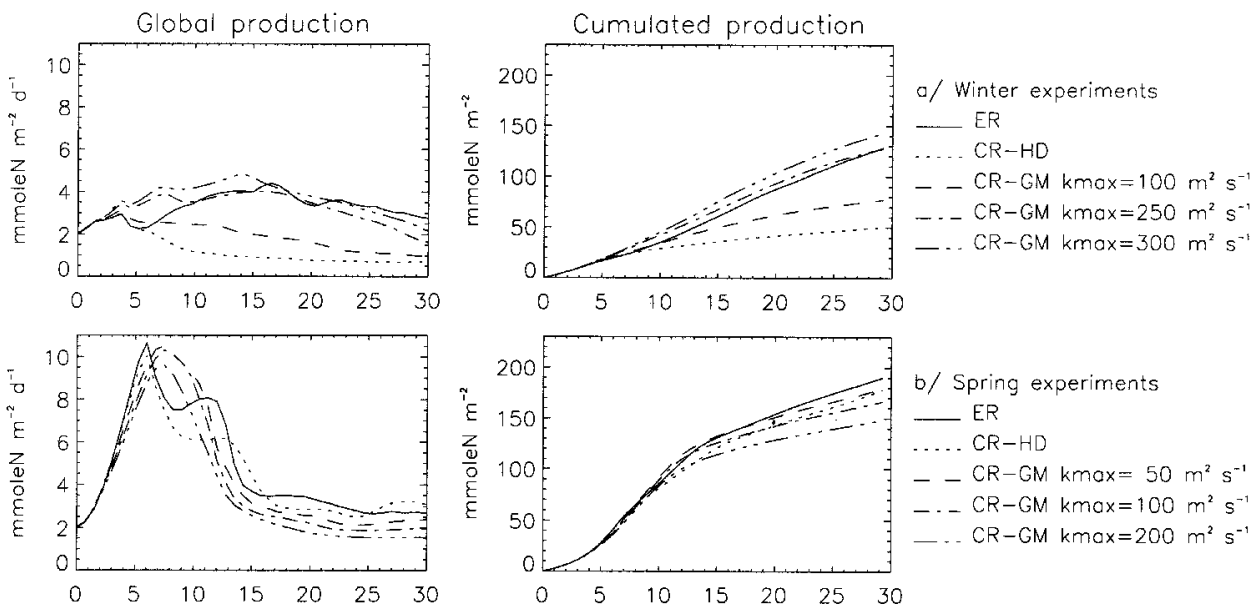

b/ Spring experiments

ER

.... CR-HD

- CR-GM kmox $=50 \mathrm{~m}^{2} \mathrm{~s}^{-1}$

- . CR-GM kmax $=100 \mathrm{~m}^{2} \mathrm{~s}^{-1}$

- . CR-GM kmax $=200 \mathrm{~m}^{2} \mathrm{~s}^{-1}$
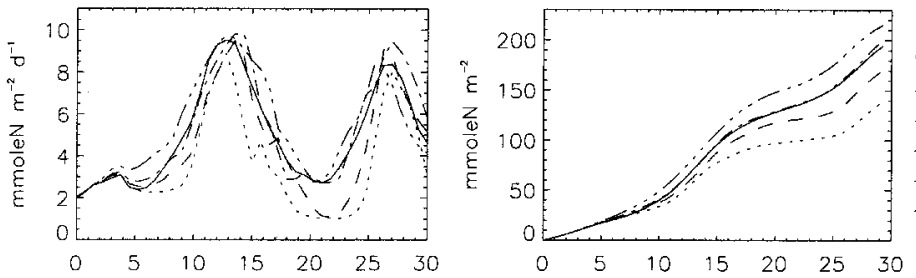

c/ T7 experiments

ER

... CR-HD

- CR-GM kmax $=50 \mathrm{~m}^{2} \mathrm{~s}^{-1}$

- . CR-GM kmox $=100 \mathrm{~m}^{2} \mathrm{~s}$

$\ldots C R-G M k m o x=200 \mathrm{~m}^{2} \mathrm{~s}^{-1}$
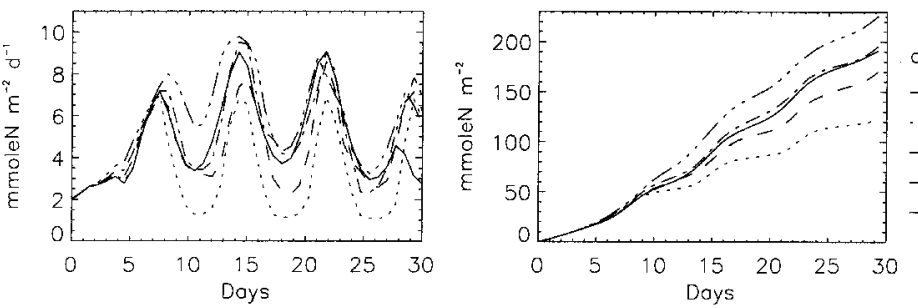

d/ T3 experiments

L ER

.... CR-HD

- $C R-G M k m a x=50 \mathrm{~m}^{2} \mathrm{~s}^{-1}$

-. CR-GM kmax $=100 \mathrm{~m}^{2} \mathrm{~s}^{-1}$

- . CR-GM kmax $=200 \mathrm{~m}^{2} \mathrm{~s}^{-1}$

Figure 10. Time series of the global and cumulated productions in the forced experiments. The solid line is for the ER runs, the dotted line for the CR-HD runs, the other types of lines for the CR-GM runs with $k_{\max }$ values as indicated.

net atmospheric forcing. However in the northwestern Mediterranean Sea, the net heat flux between winter and spring increases from a winter period when it is negative, to a spring period when it becomes positive. The increase is not necessarily steady, and can be interrupted by wind bursts that may last from a couple of days up to a week. In order to compare the GM and HD parameterizations in these different types of situations, forced experiments have been conducted in which the net heat flux was either negative ("winter" experiments), positive ("spring" experiment), or varying with a half-period of 3.75 or 7.5 days (T3 and T7 experiments). Each set of forced experiments consists of an ER experiment, an HD experiment, and a series of GM experiments with variable $k_{\max }$ (Table 1). Figure 10 shows the global and cumulated productivities for all forced experiments.

The dynamics of the instabilities in the ER experiments are only weakly affected by the 
forcing, as they rely on the whole water column structure while the forcing is only affecting the first layers (see also Lévy et al., 1999b, for similar experiments with variable forcings). Therefore, the shoaling of the mixed layer by the instabilities in the frontal zone is a feature that remains in the forced experiments. However, in addition to this local eddyrestratification, the atmospheric forcing acts to globally restratify (when it is positive) or destratify (when it is negative) the entire area.

In the ER-winter experiment (Fig. 10a), there is a competition between the restratifying action of the eddies, and the destratification caused by the atmospheric forcing. The situation is similar to that with no net forcing, however, with a systematically deeper mixed layer and therefore with smaller productivities. Regarding the CR-winter experiments, the differences between the cumulated productivities predicted using the HD or the GM parameterizations are amplified. In the HD experiment, the mixed layer progressively deepens as a response to the atmospheric forcing, and production gradually diminishes. When using the GM parameterization, the deepening of the mixed layer is partly counter-balanced in the frontal zone by the eddy induced warm water transport. Cumulated productivities reach similar values to those in the ER experiment, with a best fit obtained with a $k_{\max }$ value of $250 \mathrm{~m}^{2} \mathrm{~s}^{-1}$ (instead of $100 \mathrm{~m}^{2} \mathrm{~s}^{-1}$ in the no net flux experiment). Guided by the work of Green (1970) and Stone (1972) on baroclinic instability transfer rates, Visbeck et al. (1997) recommend a form for $k_{\max }$ proportional to the square of the horizontal stratification and inversely proportional to the vertical stratification of the large-scale flow, to be used with the GM parameterization. As a spatially homogeneous atmospheric cooling essentially decreases the vertical stratification without significantly modifying the horizontal stratification, a higher value of $k_{\max }$ would be expected. However, calculation of the difference in vertical stratification for the no net flux and winter experiment can only support a difference in $k_{\max }$ in the order of $10 \%$, far below the experimental difference that has been found. An alternative argument that supports the need for a higher $k_{\max }$ concerns the surface boundary condition. In the GM-winter experiment, the surface eddy-induced transport is confined to a deeper mixed layer than in the experiment with no net forcing (about 1.5 times deeper in the stratified area). Therefore, because the lateral mixing coefficient decreases to zero at the surface, a higher value of $k_{\max }$ is needed at the lower bound of the mixed layer to insure the same value close to the surface (Fig. 9, right panel). However, this last argument indicates the sensitivity of primary production to the value of $k_{\max }$ close to the surface. We will revisit this issue in the discussion.

In the ER-spring experiment (Fig. 10b), the warming of the surface layer by the atmosphere is sufficient to restratify the whole domain in a couple of days, causing production to rapidly rise until it becomes nutrient depleted and collapses. In such a case, where the action of the forcing is predominant over the action of the eddies, the HD and GM parameterizations give similar results, though the best fit is obtained using GM with a $k_{\max }$ value of $50 \mathrm{~m}^{2} \mathrm{~s}^{-1}$. Again, the baroclinic instability theory justifies the use of a smaller $k_{\max }$, but not as small, and the results are sensitive to the value of $k_{\max }$ close to the surface.

In the ER-T3 and ER-T7 experiments (Fig. 10c and 10d), production increases and 
decreases follow the forcing frequency; production increases occur during the transition from cooling to warming periods, in response to the associated mixed-layer shoaling; production decreases are associated with the deepening of the mixed layer resulting from the transition from a warm to a cold period. However, in the case of the T7 experiment, the depletion of nutrient toward the end of the warming period is sufficient by itself to cause the production decay, while in the T3 experiment, the forcing frequency is such that the mixed layer deepens before there has been enough time for nutrients to be utilized (not shown). When HD is used, global production is systematically underestimated, essentially during cooling periods. The use of GM can either underestimate or overestimate global production, depending on the value of $k_{\max }$; again differences are most important during cooling periods, when the eddy and thermodynamical effects are of the same order of magnitude. For both T3 and T7 experiments, the best fit for the cumulated production is obtained for a $k_{\max }$ value of $100 \mathrm{~m}^{2} \mathrm{~s}^{-1}$, which is the same value as for the no net flux experiment, and an averaged value between those of the winter and spring experiments.

\section{Discussion}

This study has shown that the use of the GM parameterization within a coarse resolution context is able to capture many aspects of the primary production enhancement associated with the restratifying action of mesoscale eddies, within the particular case of the spring bloom in the northwestern Mediterranean Sea. The quality of the results in terms of predicted primary production was all the more obvious when comparing with the HD experiments. However, predicted primary production has been shown to be quite sensitive to the parameters used in the GM parameterization, and particularly to the maximum value of the lateral mixing coefficient $k_{\max }$.

Ideally, $k_{\max }$ should be determined so as to fulfill dynamical criteria, such as the large-scale isopycnal slope, and then be used for the biology. However, in the case of the no net flux experiment, explicit calculation of $k_{\max }$ following the form recommended by Visbeck et al. (1997) gives a value ranging $300 \mathrm{~m}^{2} \mathrm{~s}^{-1}$, much higher than the one determined from the primary production criteria; and indeed, isopycnals slopes at the end of the experiment when using the value suggested by Visbeck et al. (1997) are in better agreement to those of the ER experiment than when a value of $100 \mathrm{~m}^{2} \mathrm{~s}^{-1}$ is used (Fig. 11). One of the issues that we are facing here is that the GM parameterization is a steady state parameterization, while the spring bloom obviously is not a steady state phenomena. For primary production, not only does it matter what the final state is after the dense water patch has broken up, but how fast that state is reached; and indeed, eddy-induced restratification appears to be too fast when a $k_{\max }$ coefficient of $300 \mathrm{~m}^{2} \mathrm{~s}^{-1}$ is used, which causes an overestimation of primary production.

The disagreement between the optimal values of $k_{\max }$ based on the isopycnal slopes or the primary production criteria might also hide some additional adjustment needed to correctly parameterize the biology. The fact that $k_{\max }$ needed to be adjusted when changing the atmospheric forcing makes this hypothesis all the more credible. Furthermore, numerous nonlinearities are involved in the representation of the biology, and in particular, 
DAY 30
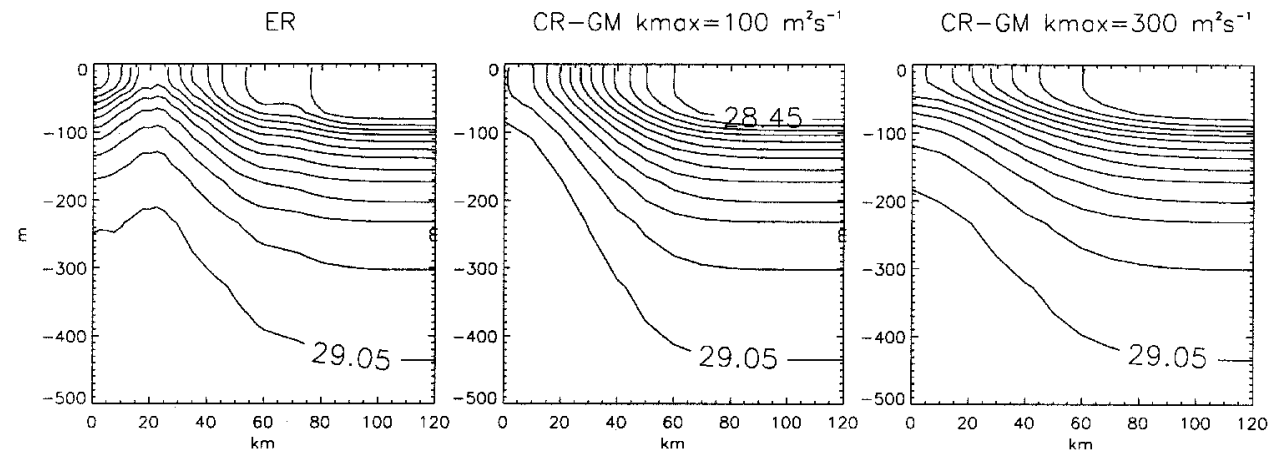

Figure 11. Azimuthally averaged density field over the top $500 \mathrm{~m}$ (contour interval is $0.05 \mathrm{~kg} \mathrm{~m}^{-3}$ ) at the end of the no net flux runs (day 30), for the ER and the CR-GM experiments with $k_{\max }$ values of 100 and $300 \mathrm{~m}^{2} \mathrm{~s}^{-1}$. The outcropping of the isopycnals at about $20 \mathrm{~km}$ from the center in the ER figure shows the signature of the eddies. The overall slope of the isopycnals in the CR-GM experiment with $k_{\max }=300 \mathrm{~m}^{2} \mathrm{~s}^{-1}$ (value recommended by Visbeck et al., 1997) is closer to that of the ER experiment than when a value of $100 \mathrm{~m}^{2} \mathrm{~s}^{-1}$ (value determined from this study on a primary production criteria) is used. Estimates of these three slopes based on the 29.00 density contours are $3.310^{-3}$ (ER), $5.210^{-3}\left(\mathrm{CR}-\mathrm{GM}, k_{\max }=100 \mathrm{~m}^{2} \mathrm{~s}^{-1}\right.$ ) and $2.810^{-3}$ (CR-GM, $\left.k_{\text {max }}=100 \mathrm{~m}^{2} \mathrm{~s}^{-1}\right)$.

production does not respond in a linear way to the mixed-layer depth, as shown by Figure 3. Therefore, it should not be possible to get the right amount of primary production with a parameterization that can only get the right averaged mixed layer, and does not account for the possible variability around this average. Following this idea, it can be attempted using the shown experiments to get an estimate of the importance of the nonlinearities. The difference between the cumulated productions obtained with $k_{\max }$ of 100 or $300 \mathrm{~m}^{2} \mathrm{~s}^{-1}$ (Fig. 8b) is of the order of $20 \%$, with global productivities differing most during the first 15 days. If we accept the interpretation of the choice of 100 instead of $300 \mathrm{~m}^{2} \mathrm{~s}^{-1}$ as a way to correct for the nonlinearities of the biology, then we can estimate these nonlinearities to account for about $20 \%$ of the primary production budget, and to be important primarily at the beginning of the experiment.

In that perspective, since the use of the GM parameterization greatly improves the prediction of primary production in this study, additional work is needed to more completely parameterize the nonlinear aspects of the biology. This will become all the more urgent for even more nonlinear biological systems, where nutrient limitation, zooplankton grazing and remineralization play an important role. But how to parameterize these nonlinearities is still an open question.

Acknowledgments. Marina Lévy acknowledges support for a Lamont Doherty Earth Observatory postdoctoral fellowship. She was then funded by the Centre National de la Recherche Scientifique (CNRS). This is Lamont Doherty Earth Observatory contribution number 5910. 


\section{APPENDIX}

\section{The NPZD biogeochemical model}

The NPZD primary production model used in this study is a simplified version of the BIOMELL biogeochemical model developed in a one-dimensional vertical framework by Lévy et al. (1998a) for the northwestern Mediterranean seasonal cycle of primary production and export fluxes. The simplification mostly concerns the regeneration and the export pathways. It was made possible by the fact that the simplified model was designed to study the winter and spring periods, when regeneration and exports are weak.

The resulting NPZD model consists of four prognostic variables (instead of ten) expressed in terms of their nitrogen content: nutrients $(N)$, phytoplankton $(P)$, zooplankton $(Z)$ and detritus $(D)$. The biogeochemical source/sink budgets for each of the variables are (with model parameters in Table A-1):

$$
\begin{gathered}
S(N)=-\mu_{p} L_{I} L_{N} P+\mu_{z} Z+\mu_{d} D \\
S(P)=\mu_{p} L_{I} L_{N} P-G_{p}-m_{p} P \\
S(Z)=a_{p} G_{p}+a_{d} G_{d}-\mu_{z} Z-m_{z} Z \\
S(D)=\left(1-a_{p}\right) G_{p}+\left(1-a_{d}\right) G_{d}+m_{p} P+m_{z} Z-\mu_{d} D-G_{z}^{d}-V_{d} \partial_{z} D .
\end{gathered}
$$

The formulation for phytoplankton growth (i.e. primary production, $\mu_{p} \mathrm{~L}_{l} \mathrm{~L}_{N} \mathrm{P}$ ) takes into account nutrient and light limitations. Nutrient limitation has the Michaelis-Menten kinetics $\left(L_{N}=N /\left(N+K_{N}\right)\right)$. Light limitation has the Webb et al. (1974) type $\left(L_{I}=\gamma_{m}\right.$ $\left(1-\mathrm{e}^{\left.\left.-\overline{\mathrm{PAR} / \mathrm{K}_{\mathrm{PR}}}\right)\right)}\right.$, modulated by a parameterization of production inhibition in situations of deep mixing through a specific coefficient $\gamma_{m} \cdot \gamma_{m}$ is set to 1 (no limitation) when the mixing layer is shallower than the euphotic layer. In such a case, cells within the mixing layer are assumed to experience a mean photosynthetic available radiation $\overline{\mathrm{PAR}}$ over the mixing layer. When the mixing layer becomes deeper than the euphotic layer, $\gamma_{m}$ decreases accordingly down to a threshold value of 0.1 (by setting $\gamma_{m}$ proportional to the ratio of the euphotic layer depth over the mixed-layer depth), and $\overline{\mathrm{PAR}}$ is taken as the averaged photosynthetic available radiation over the euphotic layer (computed as the $1 \%$ incident light depth). This parameterization has been proposed by André (1990) and yielded encouraging results in the one-dimensional study of Lévy et al. (1998a) in the northwestern Mediterranean Sea. It is based on considerations on the light experienced by the phytoplankton cells during their doubling time, which is a purely Lagrangian aspect.

Grazing of phytoplankton and detritus is formulated following Fasham et al. (1990):

$$
\begin{gathered}
G_{p}=g_{z} Z \frac{P^{2}}{(P+D) K_{z}+P^{2}+D^{2}} \\
G_{d}=g_{z} Z \frac{D^{2}}{(P+D) K_{z}+P^{2}+D^{2}} .
\end{gathered}
$$

The other biogeochemical interactions taken into account are phytoplankton mortality, 
zooplankton mortality and zooplankton excretion (these last two processes are inhibited when zooplankton concentration is below a given threshold), fecal pellet production, detritus sedimentation and detritus remineralization.

The photosynthetic available radiation (PAR) is derived from a light absorption model. Only a fraction (43\%) of the total solar radiation $Q_{\text {sol }}$ can be used for photosynthesis. Two different light wavelength are considered. The absorption coefficients $k_{r}$ and $k_{b}$ depend on the local chlorophyll concentrations Chl:

$$
\begin{aligned}
k_{r} & =k_{r 0}+\chi_{r p} \mathrm{Chl}^{e_{r}} \\
k_{b} & =k_{b 0}+\chi_{b p} \mathrm{Chl}^{e_{h}} \\
\mathrm{Chl} & =12 P R_{c: n} / R_{p i g} R_{c: c h l} \\
\operatorname{PAR}_{r}(z=0) & =\operatorname{PAR}_{b}(z=0)=0.43 Q_{s o l} / 2 \\
\operatorname{PAR}_{r}(z) & =\operatorname{PAR}_{r}(z-\Delta z) e^{-k_{r} \Delta_{z}} \\
\operatorname{PAR}_{b}(z) & =\operatorname{PAR}_{b}(z-\Delta z) e^{-k_{b} \Delta_{z}} \\
\operatorname{PAR}_{(}(z) & =\operatorname{PAR}_{r}(z)+\operatorname{PAR}_{b}(z) .
\end{aligned}
$$

The equations for the biogeochemical model are solved for the uppermost twelve model levels $(\sim 130 \mathrm{~m})$. Below, the three biogenic compartments decay to nutrients, with a decaying rate varying from one to twenty days.

Table A-1. Parameters for the NPZD model.

Nutrient half-saturation constant

Phytoplankton maximal growth rate

Carbon/Nitrogen ratio

Carbon/Chlorophyll ratio

Half-saturation constant for light

Phytoplankton mortality rate

Zooplankton maximal grazing rate

Half-saturation constant for grazing

Assimilated fraction of phytoplankton

Assimilated fraction of detritus

Excretion rate

Mortality rate

Threshold for zooplankton losses

Detritus sedimentation speed

Detritus remineralization rate

Water absorption in red

Water absorption in blue

Pigments absorption in red

Pigments absorption in blue

Exponent for power law absorption in red

Exponent for power law absorption in blue

Contribution of Chlorophyll to absorbing pigments

$\begin{array}{lll}K_{n} & 0.5 & \mathrm{mmole} / \mathrm{m}^{3} \\ \mu_{P} & 2 & \mathrm{~d}^{-1} \\ R_{c: n} & 6.6 & \mathrm{moleC} / \mathrm{moleN} \\ R_{c: c h l} & 55 & \mathrm{gC} / \mathrm{gChl} \\ K_{\mathrm{PAR}} & 33.33 & \mathrm{~W} / \mathrm{m}^{2} \\ m_{P} & 0.03 & \mathrm{~d}^{-1} \\ g_{z} & 0.75 & \mathrm{~d}^{-1} \\ K_{z} & 1 & \mathrm{mmole} / \mathrm{m}^{3} \\ a_{p} & 0.7 & \\ a_{d} & 0.5 & \\ \mu_{z} & 0.1 & \mathrm{~d}^{-1} \\ m_{z} & 0.03 & \mathrm{~d}^{-1} \\ Z_{m i n} & 0.015 & \mathrm{mmole} / \mathrm{m}^{3} \\ V_{d} & 5 & \mathrm{~m} \mathrm{~d}^{-1} \\ \mu_{d} & 0.09 & \mathrm{~d}^{-1} \\ k_{r 0} & 0.225 & \mathrm{~m}^{-1} \\ k_{b 0} & 0.0232 & \mathrm{~m}^{-1} \\ \chi_{r p} & 0.037 & \mathrm{~m}^{-1}\left(\mathrm{mg} \mathrm{Chl} / \mathrm{m}^{3}\right)^{-e_{r}} \\ \chi_{b p} & 0.074 & \mathrm{~m}^{-1}\left(\mathrm{mg} \mathrm{Chl} / \mathrm{m}^{3}\right)^{-e_{g}} \\ e_{r} & 0.629 & \\ e_{b} & 0.674 & \\ R_{p i g} & 0.7 & \end{array}$




\section{REFERENCES}

André, J.-M. 1990. Télédétection spaciale de la couleur de la mer: algorithme d'inversion des mesures du Coastal Zone Color Scanner. Applications à l'étude de la Méditerranée occidentale. $\mathrm{PhD}$, University Paris 6, France.

Blanke, B. and P. Delecluse. 1993. Variability of the tropical Atlantic Ocean simulated by a general circulation model with two different mixed-layer physics. J. Phys. Oceanogr., 23, 1363-1388.

Böning, C. W., W. R. Holland, F. O. Bryan, G. Danabasoglu and J. C. McWilliams. 1995. An overlooked problem in model simulations of the thermohaline circulation and heat transport in the Atlantic Ocean. J. Clim., 8, 515-523.

Coste, B., J. Gostan and H. J. Minas. 1972. Influence des conditions hivernales sur les productions phyto et zooplanctoniques en Méditerranée Nord-Ocidentale. I: Structures hydrologiques et distribution de sels nutritifs. Mar. Biol., 18, 320-348.

Dadou, I., V. Garçon, V. Andersen, G. Flierl and C. Davis. 1996. Impact of the North Equatorial Current meandering on a pelagic ecosystem: A modeling approach. J. Mar. Res., 54, 311-342.

Danabasoglu, G. and J. C. McWilliams. 1995. Sensitivity of the global ocean circulation to parameterizations of mesoscale tracer transports. J. Clim., 8, 2967-2987.

Danabasoglu, G., J. C. McWilliams and P. R. Gent. 1994. The role of mesoscale tracer transports in the global ocean circulation. Science, 264, 1123-1126.

Duffy, P. B., K. Caldeira, J. Selvaggi and M. I. Hoffert. 1997. Effects of subgrid-scale mixing parameterizations on simulated distributions of natural ${ }^{14} \mathrm{C}$, temperature, and salinity in a three-dimensionalocean general circulation model. J. Phys. Oceanogr., 27, 498-523.

Fasham, M. J. R., H. W. Ducklow and S. M. McKelvie. 1990. A nitrogen-based model of plankton dynamics in the oceanic mixed layer. J. Mar. Res., 48, 591-639.

Figueroa, H. A. and D. B. Olson. 1994. Eddy resolution versus eddy diffusion in a double gyre GCM. Part I: The Lagrangian and Eulerian description. J. Phys. Oceanogr., 24, 371-386.

Flierl, G. and C. S. Davis. 1993. Biological effects of Gulf Stream meandering. J. Mar. Res., 51, 529-560.

Gent, P. and M. A. Cane. 1989. A reduced gravity, primitive equation model of the upper equatorial ocean. J. Comput. Phys., 81, 444-480.

Gent, P. and J. McWilliams. 1990. Isopycnal mixing in ocean circulation models. J. Phys. Oceanogr., $20,150-155$.

Gent, P. R., J. Willebrand, T. J. McDougall and J. C. McWilliams. 1995. Parameterizing eddy induced transports in ocean circulation models. J. Phys. Oceanogr., 25, 463-474.

Gower, J. F. R., K. L. Denman and R. L. Holyer. 1980. Phytoplankton patchiness indicates the fluctuations spectrum of mesoscale oceanic structure. Nature, 288, 157-159.

Green, J. S. 1970. Transfer properties of the large scale eddies and the general circulation of the atmosphere. Quart. J. Roy. Meteor. Soc., 96, 157-185.

Griffies, S. M., A. Gnanadesikan, R. C. Pacanowski, V. D. Larichev, J. K. Dukowicz and R. D. Smith. 1998. Isoneutral diffusion in a z-coordinate ocean model. J. Phys. Oceanogr., 28, 805-830.

Jacques, G., H. J. Minas, M. Minas and P. Nival. 1973. Influence des conditions hivernales sur les productions phyto et zooplanctoniques en Méditerranée Nord-Occidentale. II: Biomasse et production phytoplanctonique.Mar. Biol., 23, 251-265.

Leaman, K. D. and F. A. Schott. 1987. Hydrographic structure of the convection regime in the Gulf of Lions: Winter 1987. J. Phys. Oceanogr., 21, 575-598.

Lévy, M., L. Mémery and J.-M. André. 1998a. Simulation of primary production and export fluxes in the northwestern Mediterranean Sea. J. Mar. Res., 56, 197-238.

Lévy, M., L. Mémery and G. Madec. 1998b. The onset of a bloom after deep winter convectionin the North Western Mediterranean Sea: mesoscale process study with a primitive equation model. J. Mar. Syst., 16, 7-21. 
1999a. The onset of a bloom in the MEDOC area: Mesoscale spatial variability. Deep-Sea Res., 46/7, 1137-1160.

— 1999b. Combined effects of mesoscale processes and atmospheric high-frequency variability on the spring bloom in the MEDOC area. Deep-Sea Res. (in press).

McGillicuddy, D. J., A. R. Robinson and J. J. McCarty. 1995. Coupled physical and biological modelling of the spring bloom in the North Atlantic (II): three dimensional bloom and post-bloom processes. Deep-Sea Res., 42, 1359-1398.

Medoc Group. 1970. Observation of formation of deep water in the Mediterranean Sea, 1969. Nature, 227, 1037-1040.

Moisan, J. R., E. E. Hofmann and D. B. Haidvogel. 1996. Modeling nutrient and phytoplankton processes in the California coastal transition zone. 2. A three-dimensional physical-bio-optical model. J. Geophys. Res., 101, 22677-22691.

Naik, N. 1998. Lamont Ocean-AML Model (LOAM) documentation, http://www.ldeo.columbia.edu

Oschlies, A. and V. Garçon. 1998. Eddy-induced enhancement of primary production in a model of the North Atlantic Ocean. Nature, 394, 266-269.

Pacanowski, R. C. and S. G. H. Philander. 1981. Parameterization of vertical mixing in numerical models of tropical oceans. J. Phys. Oceanogr., 11, 1443-1451.

Pedlosky, J. 1987. Geophysical Fluid Dynamics, 2nd ed., Springler-Verlag, NY, 710 pp.

Rix, N. H. and J. Willebrand. 1996. Parameterization of mesoscale eddies as inferred from a high-resolution circulation model. J. Phys. Oceanogr., 26, 2281-2285.

Robinson, A. R., D. J. McGillicuddy, J. Calman, H. W. Ducklow, M. J. R. Fasham, F. E. Hoge, W. G. Leslie, J. J. McCarthy, S. Podewski, D. L. Porter, G. Saure and J. A. Yoder. 1993. Mesoscale and upper ocean variabilities during the 1989 JGOFS bloom study. Deep-Sea Res., 40, 9-35.

Rodgers, K., M. Cane, N. Naik and D. Schrag. 1999. The role of the Indonesian throughflow in equatorial Pacific thermocline ventilation. J. Geophys. Res., (in press).

Schott, F., M. Visbeck, U. Send, J. Fischer, L. Stramma and Y. Desaubies. 1996. Observations of deep convection in the Gulf of Lions, Northwestern Mediterranean, during the winter 1991/92. J. Phys. Oceanogr., 26, 505-524.

Shapiro, R. 1970. Smoothing, filtering, and boundary effects. Rev. Geophys. Space Phys., 8, 359-387.

Smith, C. L., K. J. Richards and M. J. R. Fasham. 1996. The impact of mesoscale eddies on plankton dynamics in the upper ocean. Deep-Sea Res., 43, 1807-1832.

Stone, P. 1972. A simplified radiative dynamical model for the static stability of rotating atmospheres. J. Atmos. Sci., 29, 405-418.

Treguier, A. M., I. M. Held and V. D. Larichev. 1997. On the parameterization of quasi-geostrophic eddies in primitive equation ocean models. J. Phys. Oceanogr., 27, 567-580.

Visbeck, M., J. Marshall, T. Haine and M. Spall. 1997. On the specification of eddy transfer coefficients in coarse resolution ocean circulation models. J. Phys. Oceanogr., 27, 381-402.

Watson, A. J., C. Robinson, J. E. Robinson, P. J. L. B. Williams and M. J. R. Fasham. 1991. Spatial variability in the sink for atmospheric carbon dioxide in the North Atlantic. Nature, 350, 50-53.

Webb, W. L., M. Newton and D. Starr. 1974. Carbon dioxide exchange of Alnus Rubra: A mathematical model. Ecologia, 17, 281-291.

Yoshimori, A. and M. J. Kishi. 1994. Effects of interaction between two warm-core rings on phytoplankton distribution. Deep-Sea Res., 41, 1039-1052.

Received: 22 December, 1998; revised: 4 March, 1999. 